\title{
Pulse Wave Velocity in End-Stage Renal Disease: Influence of Age and Body Dimensions
}

\author{
ÉVA KIS, ORSOLYA CSEPREKÁL, ZSÓFIA HORVÁTH, GÁBOR KATONA, BERTALAN C. FEKETE, ERZSÉBET HRAPKA, \\ ANDRÁS SZABÓ, ATTILA J. SZABÓ, ANDREA FEKETE, AND GYÖRGY S. REUSZ
}

\author{
First Department of Pediatrics [E.K., O.C., Z.H., G.K., E.H., A.J.S., A.F., G.S.R.], First Department of Internal Medicine [B.C.F.], \\ Semmelweis University, Budapest, Hungary, 1083; Szentágothai János Knowledge Center [A.S.], Budapest, Hungary, 1056
}

\begin{abstract}
Arterial stiffness increases with age. This process is accelerated by end-stage renal disease (ESRD). Pulse wave velocity (PWV) increases with arterial stiffness. In this study, PWV of 133 healthy individuals (6-23 y of age) and 11 patients on dialysis was measured to establish the normal values of PWV and to compare them with those in ESRD. Age-matched (A-C) and height- and weight-matched (H/W-C) control groups were used. Thereafter, PWV was indexed to height and the data were reevaluated. The role of the risk factors including serum calcium, phosphate, parathyroid hormone (PTH), and the time on dialysis was analyzed using a score system. PWV correlated with age, weight, height, blood pressure, and heart rate. ESRD patients were smaller than A-C and older than H/W-C. PWV of patients with ESRD did not differ from A-C; however, it was elevated in comparison to H/W-C. In both healthy and ESRD patients, the PWV/height ratio was independent of age. PWV/height was increased in ESRD. There was a correlation between PWV/height and the risk factor score. Controls matched for height and weight or PWV/height should be used in cases of growth failure. A number of risk factors responsible for increased arterial stiffness are present in ESRD. (Pediatr Res 63: 95-98, 2008)
\end{abstract}

$\mathrm{C}$ ardiovascular disease is the leading cause of death among patients with end stage renal disease (ESRD) (1). The causes are multifactorial, and include alterations of calciumphosphate homeostasis and lipid metabolism, chronic inflammation, systemic hypertension, and chronic anemia, leading together to accelerated arteriosclerosis, atherosclerosis, and left ventricular hypertrophy (2-5). One consequence of changes in the arterial wall composition in uremia is an increase in arterial wall stiffness. Valuable information on arterial properties such as stiffness can be obtained from noninvasive measurement of the pulse wave velocity (PWV) (6,7). Accelerated arteriosclerosis was recently described in young adults with $\operatorname{ESRD}(8,9)$; data on PWV in uremic children is sparse (10).

As PWV is influenced by age, our aim was to a) establish normal values for PWV in a healthy pediatric population and b) to compare it with children on dialysis. Blood pressure, calcium $(\mathrm{Ca})$, phosphate $(\mathrm{P})$, and parathyroid hormone $(\mathrm{PTH})$

Received March 14; accepted August 10, 2007

Correspondence: György S. Reusz, M.D., Ph.D., First Department of Pediatrics, Semmelweis University, Budapest, Bókay u. 53, H-1083; e-mail: reusz@gyer1.sote.hu The study was supported by the National Scientific Research Grants OTKA-T046155F048842-F042563, ETT 435/2006, the Semmelweis Foundation, and by the Szentágothai János Knowledge Center (A.S.). A.F. is a recipient of the "Magyary" and A.J.S. is a recipient of the "Bolyai" scholarship.

É.K. and O.C. contributed equally to the manuscript. levels were also analyzed as known cardiovascular risk factors.

\section{PATIENTS AND METHODS}

Patients with ESRD. Eleven patients receiving maintenance dialysis participated in the study. The diagnoses leading to ESRD were (number of patients in parentheses): focal-segmental glomerulosclerosis (4), autosomal recessive polycystic kidney disease (2), renal hypoplasia and vesicoureteral reflux (2), chronic glomerulonephritis (1), Alport syndrome (1), and juvenile nephronophthisis (1). Four children were treated with peritoneal dialysis and seven with hemodialysis. Two patients had transplants previously, but returned to dialysis due to chronic rejection.

Eight children were treated with an angiotensin-converting enzyme (ACE) inhibitor, enalapril, and six with enalapril and a calcium channel blocker, amlodipine. They were normotensives on medication. Three patients had normal blood pressure without antihypertensive treatment.

Control population for $P W V$ measurements. PWV was measured in 133 healthy children and young adults aged 6-23 y (13.01 $\pm 3.76 \mathrm{y})$. Using the database of the 133 healthy controls, two subgroups of children consisting of 11 , respectively, were formed. One was adjusted to the patient's age and gender (children with date of birth closest to the patient's data were selected). The other was adjusted to the height, weight, and gender (children with height and weight closest to the patient's values were selected).

Furthermore, in search of a more universal technique of comparison, the effect of indexing PWV to height $(\mathrm{m})$, weight $(\mathrm{kg})$, and BSA (body surface area, $\mathrm{m}^{2}$ ) was assessed.

Control population for laboratory data. Leftover serum samples of 40 children evaluated for minor surgical interventions were used anonymously as control for $\mathrm{Ca}, \mathrm{P}$, creatinine, and $\mathrm{PTH}$.

Basic characteristics of the patients and the control groups are shown in Table 1.

PWV measurements. PWV is the speed of travel of the pulse along an arterial segment. Aortic PWV is defined as the distance of the sampling sites divided by the time difference between the rise delay of the distal and proximal pulse according to the $\mathrm{R}$ wave belonging to the ECG qRs complex.

PWV was measured by sequential recordings of the arterial pressure wave at the carotid and femoral arteries and by measurement of the distance from the carotid sampling site to the suprasternal notch and from the suprasternal notch to the femoral sampling site. Arterial pressure wave was recorded by applanation tonometry (11) using the validated PulsePen device (DiaTecne s.r.1., Milan, Italy) interfaced with a computer. The probe was connected to a hand-held ECG-unit. Both pressure and electrocardiographic signals were transmitted to a computer to be displayed and processed. The pulse wave was calibrated by measuring BP immediately before the recordings. The specially designed software provides absolute arterial pressure values, an assessment of arterial pulse wave contours, an estimation of reflection waves, and measurements of PWV (12). We discarded recordings when the systolic or diastolic variability of consecutive waveforms was $>10 \%$ or when the amplitude of the pulse wave signal was $<80 \mathrm{mV}$.

Laboratory measurements. $\mathrm{Ca}, \mathrm{P}$, and creatinine were measured by routine laboratory methods on a Hitachi autoanalyzer. Intact (1-84) PTH (iPTH) was determined by immunochemiluminometric two-site assay (CIBA-

Abbreviations: ESRD, end-stage renal disease; PWV, pulse wave velocity; UB, uremic burden 
Table 1. Clinical data of the patients with ESRD and the control groups

\begin{tabular}{|c|c|c|c|c|c|}
\hline & Gender $\mathrm{m} / \mathrm{f}$ & $\begin{array}{c}\text { RRT } \\
\text { HD/CAPD }\end{array}$ & $\begin{array}{c}\text { Age } \\
\text { mean (SD), y }\end{array}$ & $\begin{array}{c}\text { Weight } \\
\text { mean }(\mathrm{SD}), \mathrm{kg}\end{array}$ & $\begin{array}{c}\text { Height } \\
\text { mean }(\mathrm{SD}), \mathrm{m}\end{array}$ \\
\hline ESRD & $8 / 3$ & $7 / 4$ & $14.3(4.1)$ & $36.9(15.5)$ & $1.415(0.206)$ \\
\hline Control (age adjusted) & $8 / 3$ & - & $14.5(4.3)$ & $46.6(15.6)^{*}$ & $1.562(0.197) \S$ \\
\hline Control (height/weight adjusted) & $8 / 3$ & - & $10.7(2.6)^{* *}$ & $36.7(19.7)$ & $1.409(0.156)$ \\
\hline
\end{tabular}

RRT, renal replacement therapy; HD, hemodialysis; CAPD, chronic ambulatory peritoneal dialysis.

$* p<0.05 v s$ ESRD and height/weight-adjusted control.

$* * p<0.01 v s$ ESRD and age-adjusted control.

$\S p<0.01 v s$ ESRD and height/weight-adjusted control.

CORNING, Fernwald, Germany). The reference range of the assay is 9-60 $\mathrm{pg} / \mathrm{mL}(13)$

Evaluation of the effect of ESRD. To characterize the impact of the persistent uremic environment - the "uremic burden" (UB) — we introduced a scoring system. High-normal serum calcium $(\mathrm{Ca}>2.2 \mathrm{mM})$, elevated serum phosphate $(\mathrm{P}>1.8 \mathrm{mM})$, PTH $(>180 \mathrm{pg} / \mathrm{mL})$, and the time on dialysis beyond 12 mo were scored as 1 . Values below these limits were scored 0 .

Statistical analysis. Data management was performed using the STATISTICA7.1. software (StatSoft, Inc., Tulsa, OK). All data are presented as mean (SD). Data were compared using $t$ test. Linear and multiple linear regression analysis were performed for the assessment of possible associations between PWV and other variables. A $p$ value $<0.05$ was considered statistically significant.

The study conformed to the Helsinki declaration and was approved by the Ethical Committee of the Semmelweis University. Parental informed consent was obtained from all healthy children in the control group and from the patients with ESRD participating in the study.

\section{RESULTS}

Healthy controls. The mean PWV of the 133 healthy children (male: 60, female: 73) was $5.02(0.89) \mathrm{m} / \mathrm{s}$. There was a significant linear correlation between PWV and age, height, weight, and systolic and diastolic blood pressure and a significant negative correlation to the heart rate. Values of the individual correlations are shown in Table 2.

By multivariate analysis, only age remained the significant determinant of PWV (Beta: 0.74, SE: 0.16, $p<0.0001$ ).

Patients with ESRD. As shown in Table 1, patients with ESRD were significantly shorter and lighter than the agematched controls. Further, they were significantly older than their height- and weight-matched healthy pairs.

The hemodynamic and laboratory parameters of the patient and the control groups are shown in Table 3.

The PWV of the patients with ESRD did not differ significantly from the age-matched group. On the contrary, patients with ESRD had significantly increased PWV compared with the height/weight-matched control group.

Table 2. Correlations between $P W V$ and age, weight, height, systolic, diastolic blood pressure, and heart rate in 133 healthy children and young adults

\begin{tabular}{lcl}
\hline & $R$ & $p$ Value \\
\hline Age & 0.64 & $<0.00001$ \\
Weight & 0.47 & $<0.00001$ \\
Height & 0.53 & $<0.00001$ \\
RRsy & 0.39 & $<0.0001$ \\
RRdia & 0.21 & $<0.02$ \\
HR & -0.35 & $<0.0001$
\end{tabular}

RRsy, systolic blood pressure; RRdia, diastolic blood pressure; HR, heart rate.
There was no difference between the blood pressure (expressed as Z-score) and heart rate parameters of the patients with ESRD and either of the control groups.

Patients with ESRD had significantly elevated creatinine, lower calcium, and increased phosphate and iPTH compared with the controls.

There was no significant correlation between the PWV and any of the serum parameters measured.

Indexing PWV to weight or BSA did not suppress the age dependence of the indexed variables $(r=-0.55, p<0.001$, and $r=-0.41, p<0.001$, respectively). However, age dependence disappeared completely following indexing PWV to height $(r=0.03, p=\mathrm{NS})$.

Based on the novel parameter the PWV/height, the ESRD group differed significantly from both age-matched control (A-C) and height/weight matched control (H/W-C) groups as well as from the whole control group (ESRD: $4.02 \pm 0.751 / \mathrm{s}$ versus control: $3.27 \pm 0.491 / \mathrm{s} ; p<0.0001)$. There were no differences between the PWV/height values of the A-C and $\mathrm{H} / \mathrm{W}-\mathrm{C}$ groups (Table 3 ).

The individual values of $\mathrm{Ca}, \mathrm{P}, \mathrm{PTH}$, and time on dialysis as well as PWV/height and the UB score are shown in Table 4.

The PWV/height values of the group with one or two risk factors were significantly lower than those of patients with three or four risk factors $(3.46 \pm 0.371 / \mathrm{s}$ versus $4.62 \pm 0.5$ $1 / \mathrm{s} ; p<0.01$, respectively).

Furthermore, a significant correlation could be shown between PWV/height and the UB score expressed as the sum of the individual risk factors $(r=0.61, p<0.05)$ (Fig. 1).

\section{DISCUSSION}

There is a continuous increase of PWV with age, due to geometric and structural changes of the vessel walls during growth and physiologic aging. This study confirmed the close correlation between PWV and age in children. Due to the close relation between age, height, and weight during growth, only age remained the independent variable correlating with PWV in healthy children (14).

Uremia increases the risk of cardiovascular mortality due to accelerated arteriosclerosis (15). The increase of PWV was established as a useful measure to characterize arterial stiffness in adult hypertension and ESRD (16-18).

As described recently, premature vascular calcification is already present in young patients with $\operatorname{ESRD}(19,20)$. It seemed obvious that arterial dysfunction in children with 
Table 3. Comparison of PWV, PWV/height, blood pressure, and heart rate values of patients with ESRD and the control groups adjusted for age and for height and weight, and of the laboratory data

\begin{tabular}{|c|c|c|c|c|c|c|c|c|c|}
\hline & $\begin{array}{c}\mathrm{PWV} \\
\mathrm{m} / \mathrm{s}\end{array}$ & $\begin{array}{c}\mathrm{PWV} / \text { height } \\
1 / \mathrm{s}\end{array}$ & $\begin{array}{c}\text { RRsy } \\
\text { Z-score }\end{array}$ & $\begin{array}{l}\text { RRdia } \\
\text { Z-score }\end{array}$ & $\begin{array}{c}\mathrm{HR} \\
1 / \mathrm{min}\end{array}$ & $\begin{array}{c}\text { Creatinine } \\
\mu \mathrm{mol} / \mathrm{L}\end{array}$ & $\begin{array}{c}\mathrm{Ca} \\
\mathrm{mmol} / \mathrm{L}\end{array}$ & $\begin{array}{c}\mathrm{P} \\
\mathrm{mmol} / \mathrm{L}\end{array}$ & $\begin{array}{c}\mathrm{PTH} \\
\mathrm{pg} / \mathrm{mL}\end{array}$ \\
\hline ESR & 94) & $0(0.75)$ & 89) & 0.67 & $79(21)$ & 745 & 2.21 & 2.35 & $618(549)$ \\
\hline Control (age adjusted) & $5.01(1.07)$ & $3.17(0.6)^{*}$ & $0.24(0.75)$ & $0.37(0.36)$ & $74(11)$ & $74(13) \S$ & $2.55(0.13)^{*}$ & $1.35(2.75)^{*}$ & $34(5) \S$ \\
\hline Control (height/weight adjusted) & $4.56(0.50)^{*}$ & $3.23(0.49)^{*}$ & $0.46(0.54)$ & $0.44(0.45)$ & $84(9) * *$ & & & & \\
\hline
\end{tabular}

RRsy, systolic blood pressure; RRdia, diastolic blood pressure; HR, heart rate.

$* p<0.01 v s$ ESRD; $* * p<0.02 v s$ age-adjusted controls; $\$ p<0.001$ vs ESRD.

Table 4. Values of serum calcium, phosphate, PTH, time on dialysis, $P W V /$ height, and the score of the $U B$

\begin{tabular}{lcccccc}
\hline Patient & $\begin{array}{c}\text { Se Ca } \\
(\mathrm{mmol} / \mathrm{L})\end{array}$ & $\begin{array}{c}\text { Se P } \\
(\mathrm{mmol} / \mathrm{L})\end{array}$ & $\begin{array}{c}\text { PTH } \\
(\mathrm{pg} / \mathrm{mL})\end{array}$ & $\begin{array}{c}\text { Time } \\
\text { on dialysis } \\
(\mathrm{mo})\end{array}$ & $\begin{array}{c}\text { PWV/ } \\
\text { height } \\
(1 / \mathrm{s})\end{array}$ & UB score \\
\hline 1 & 2.2 & 2.1 & 227 & 0 & 3.35 & 2 \\
2 & 2.4 & 2.0 & 121 & 3 & 3.58 & 2 \\
3 & 2.4 & 2.0 & 1588 & 3.5 & 5.11 & 3 \\
4 & 2.4 & 2.5 & 315 & 5 & 4.78 & 3 \\
5 & 2.5 & 1.8 & 170 & 5 & 3.86 & 1 \\
6 & 2 & 3.1 & 692 & 11 & 3.65 & 2 \\
7 & 2.2 & 0.7 & 108 & 14 & 2.86 & 1 \\
8 & 2.2 & 3.6 & 197 & 42 & 4.49 & 3 \\
9 & 2.3 & 3.0 & 1459 & 43 & 3.68 & 4 \\
10 & 1.9 & 2.9 & 1010 & 73 & 4.78 & 3 \\
11 & 1.8 & 2.2 & 912 & 78 & 4.94 & 3 \\
Mean & 2.21 & 2.35 & 618 & 25.2 & 4.10 & \\
SD & 0.23 & 0.79 & 549 & 29.0 & 0.75 & \\
\hline
\end{tabular}

Individual elements of the UB score: $\mathrm{Ca}>2.2, \mathrm{P}>1.8, \mathrm{PTH}>180$, Time on dialysis $>12 \mathrm{mo}$.

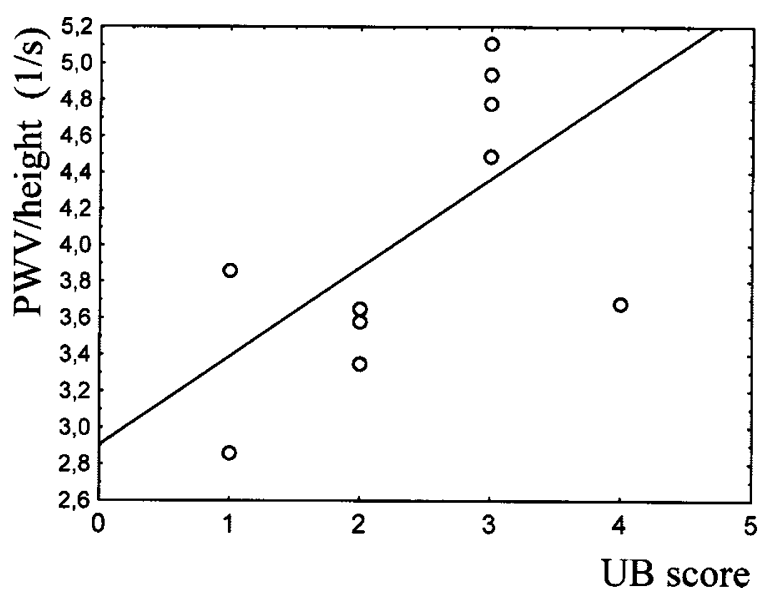

Figure 1. Correlation between the UB score and PWV/height, $\mathrm{Y}=0.4869 *$ $\mathrm{X}+2.9031 ; R=0.61, p<0.05$.

ESRD could be reflected in the changes of PWV. However, our first analysis, i.e. when we used data of age-matched healthy children, presented only a weak tendency of increased PWV in uremia. At the same time, the analysis revealed that the patient group's body dimensions (weight and height) were significantly below those of the controls, due to the deleterious effect of uremia on growth (21).

The use of controls matched by height or weight is a well-established necessity in pediatrics. Bone mineral density and blood pressure are examples where specific patient populations require a thoughtful selection of their control pairs rather than the automated use of age matched controls (22-
25). Thus, using a height- and weight-matched control group, we did indeed find a significantly increased PWV in ESRD, whereas the other hemodynamic parameters did not differ significantly.

In the search of a universal measure of PWV in children, we found that indexing PWV to height provides a parameter independent of age. The PWV/height of the patients with ESRD differed significantly not only from the control group, but also from both special subgroups (i.e. from the age matched on one hand and the height and weight matched on the other).

Disturbed calcium and phosphate metabolism is among the main factors leading to vascular calcification in uremic adults (26-28) and in children (29).

Compared with healthy controls, our patients had significantly elevated creatinine, P, and PTH levels. To assess the relation between the UB and PWV/height, we established an arbitrary scoring system (the UB score) based on serum $\mathrm{Ca}, \mathrm{P}$, and PTH levels and the time spent on dialysis.

Although the choice of the score is arbitrary, the individual elements used are well-established factors of cardiovascular risk in adults as well as in children $(19,20,30,31)$.

Using the scoring system, patients with one or two risk factors had significantly lower PWV/height values than those rating higher. There was also a significant correlation between $\mathrm{PWV} /$ height and scores of the individual patients.

The lack of direct correlation between those parameters and $\mathrm{PWV}$ or PWV/height might be explained by the small sample size and the cross-sectional nature of the present study: the snapshot of the individual parameters does not necessarily reflect the atherogenic burden inflicted during the long-lasting development of the end-stage renal disease.

As already mentioned, the small sample size and the crosssectional design of the study is a serious obstacle to a moredetailed analysis. As individual pediatric dialysis units have a limited number of patients compared with adult facilities, a multicenter prospective approach is needed to establish the biologic significance of the results presented.

A confounding factor influencing arterial stiffness and PWV might be the use of antihypertensive drugs. However, ACE inhibitors and vasodilators such as calcium channel blockers are known to decrease arterial stiffness and PWV via delayed return of the reflected wave from the periphery to the heart while decreasing its amplitude and systolic duration (32-34). Thus, our patients had increased PWV despite the possible positive effect of antihypertensive treatment. A withdrawal of the antihypertensive drugs was not considered for ethical reasons. 
In conclusion, this study demonstrates increased PWV as a sign of increased arterial stiffness in children with ESRD. It also points out the necessity of the use of appropriate controls in special pediatric populations. Thus, controls matched for height and weight should be used in cases of growth failure. Indexing PWV to height (PWV/height) provides a universal parameter to circumvent the problem of growth retardation.

Children with more risk factors involving calcium and phosphate homeostasis have higher PWV/height, suggesting the role of disturbed calcium metabolism.

\section{REFERENCES}

1. Sarnak MJ, Levey AS, Schoolwerth AC, Coresh J, Culleton B, Hamm LL, McCullough PA, Kasiske BL, Kelepouris E, Klag MJ, Parfrey P, Pfeffer M, Raij L, Spinosa DJ, Wilson PW 2003 Kidney disease as a risk factor for development of cardiovascular disease: a statement from the American Heart Association Councils on Kidney in Cardiovascular Disease, High Blood Pressure Research, Clinical Cardiology, and Epidemiology and Prevention. Hypertension 42:1050-1065

2. Block GA, Hulbert-Shearon TE, Levin NW, Port FK 1998 Association of serum phosphorus and calcium $\mathrm{x}$ phosphate product with mortality risk in chronic hemodialysis patients: a national study. Am J Kidney Dis 31:607-617

3. Ganesh SK, Stack AG, Levin NW, Hulbert-Shearon T, Port FK 2001 Association of elevated serum $\mathrm{PO}(4), \mathrm{Ca} \times \mathrm{PO}(4)$ product, and parathyroid hormone with cardiac mortality risk in chronic hemodialysis patients. J Am Soc Nephrol 12:2131-2138

4. Appel LJ 2004 Beyond (or back to) traditional risk factors: preventing cardiovascular disease in patients with chronic kidney disease. Ann Intern Med 140:60-61

5. Varma R, Garrick R, McClung J, Frishman WH 2005 Chronic renal dysfunction as an independent risk factor for the development of cardiovascular disease. Cardiol Rev 13:98-107

6. Nichols WW 2005 Clinical measurement of arterial stiffness obtained from noninvasive pressure waveforms. Am J Hypertens 18:3S-10S

7. Blacher J, Guerin AP, Pannier B, Marchais SJ, Safar ME, London GM 1999 Impact of aortic stiffness on survival in end-stage renal disease. Circulation 99:2434-2439

8. Goodman WG, Goldin J, Kuizon BD, Yoon C, Gales B, Sider D, Wang Y, Chung J, Emerick A, Greaser L, Elashoff RM, Salusky IB 2000 Coronary-artery calcification in young adults with end-stage renal disease who are undergoing dialysis. N Engl J Med 342:1478-1483

9. Oh J, Wunsch R, Turzer M, Bahner M, Raggi P, Querfeld U, Mehls O, Schaefer F 2002 Advanced coronary and carotid arteriopathy in young adults with childhoodonset chronic renal failure. Circulation 106:100-105

10. Covic A, Mardare N, Gusbeth-Tatomir P, Brumaru O, Gavrilovici C, Munteanu M, Prisada O, Goldsmith DJ 2006 Increased arterial stiffness in children on haemodialysis. Nephrol Dial Transplant 21:729-735

11. Matthys K, Verdonck P 2002 Development and modelling of arterial applanation tonometry: a review. Technol Health Care 10:65-76

12. Salvi P, Lio G, Labat C, Ricci E, Pannier B, Benetos A 2004 Validation of a new non-invasive portable tonometer for determining arterial pressure wave and pulse wave velocity: the PulsePen device. J Hypertens 22:2285-2293

13. Reusz GS, Dobos M, Vásárhelyi B, Sallay P, Szabo A, Horvath C, Szabo A, Byrd DJ, Thole HH, Tulassay T 1998 Sodium transport and bone mineral density in hypercalciuria with thiazide treatment. Pediatr Nephrol 12:30-34
14. Cheung YF, Brogan PA, Pilla CB, Dillon MJ, Redington AN 2002 Arterial distensibility in children and teenagers: normal evolution and the effect of childhood vasculitis. Arch Dis Child 87:348-351

15. Ketteler M, Westenfeld R, Schlieper G, Brandenburg V 2005 Pathogenesis of vascular calcification in dialysis patients. Clin Exp Nephrol 9:265-270

16. Laurent S, Boutouyrie P, Asmar R, Gautier I, Laloux B, Guize L, Ducimetiere P, Benetos A 2001 Aortic stiffness is an independent predictor of all-cause and cardiovascular mortality in hypertensive patients. Hypertension 37:1236-1241

17. Shinohara K, Shoji T, Tsujimoto Y, Kimoto E, Tahara H, Koyama H, Emoto M, Ishimura E, Miki T, Tabata T, Nishizawa Y 2004 Arterial stiffness in predialysis patients with uremia. Kidney Int 65:936-943

18. London GM, Marchais SJ, Guerin AP 2004 Arterial stiffness and function in end-stage renal disease. Adv Chronic Kidney Dis 11:202-209

19. Querfeld U 2004 The clinical significance of vascular calcification in young patients with end-stage renal disease. Pediatr Nephrol 19:478-484

20. Eifinger F, Wahn F, Querfeld U, Pollok M, Gevargez A, Kriener P, Gronemeyer D 2000 Coronary artery calcifications in children and young adults treated with renal replacement therapy. Nephrol Dial Transplant 15:1892-1894

21. Kari JA, Rees L 2005 Growth hormone for children with chronic renal failure and on dialysis. Pediatr Nephrol 20:618-621

22. Schönau E 1998 Problems of bone analysis in childhood and adolescence. Pediatr Nephrol 12:420-429

23. Reusz GS, Szabó AJ, Péter F, Kenesei É, Sallay P, Latta K, Szabó A, Szabó A, Tulassay T 2000 Bone metabolism and mineral density following renal transplantation. Arch Dis Child 83:146-151

24. National High Blood Pressure Education Program Working Group on High Blood Pressure in Children and Adolescents 2004 The fourth report on the diagnosis, evaluation, and treatment of high blood pressure in children and adolescents. Pediatrics 114:555-576

25. Soergel M, Kirschstein M, Busch C, Danne T, Gellermann J, Holl R, Krull F, Reichert H, Reusz GS, Rascher W 1997 Oscillometric twenty-four hour ambulatory blood pressure values in healthy children and adolescents. A multicenter trial including 1141 healthy subjects. J Pediatr 130:178-184

26. Giachelli CM 2004 Vascular calcification mechanisms. J Am Soc Nephrol 15:2959_ 2964

27. Moe SM 2006 Vascular calcification: hardening of the evidence. Kidney Int 70:1535-1537

28. London GM 2003 Cardiovascular calcifications in uremic patients: clinical impact on cardiovascular function. J Am Soc Nephrol 14:S305-S309

29. Moe SM, Chen NX 2003 Calciphylaxis and vascular calcification: a continuum of extra-skeletal osteogenesis. Pediatr Nephrol 18:969-975

30. Qunibi WY 2004 Consequences of hyperphosphatemia in patients with end-stage renal disease (ESRD). Kidney Int Suppl 90:S8-S12

31. Blaszak RT, Mitsnefes MM, Ilyas M, Salman SD, Belcher SM, Brady DR 2005 Hyperphosphatemia in children receiving peritoneal dialysis-an educational program. Pediatr Nephrol 20:967-971

32. O'Rourke MF 1999 Wave travel and reflection in the arterial system. J Hypertens Suppl 17:S45-S47

33. Asmar RG, London GM, O'Rourke ME, Safar ME 2001 Improvement in blood pressure, arterial stiffness and wave reflections with a very-low-dose perindopril/ indapamide combination in hypertensive patient: a comparison with atenolol. Hypertension 38:922-926

34. London GM, Asmar RG, O'Rourke MF, Safar ME REASON Project Investigators 2004 Mechanism(s) of selective systolic blood pressure reduction after a low-dose combination of perindopril/indapamide in hypertensive subjects: comparison with atenolol. J Am Coll Cardiol 43:92-99 